\title{
Simultaneous free-volume modeling of the self-diffusion coefficient and dynamic viscosity at high pressure
}

Boned, C.; Allal, A.; Baylaucq, A.; Zéberg-Mikkelsen, Claus; Bessieres, D.; Cisneros, Sergio

Published in:

Physical Review E. Statistical, Nonlinear, and Soft Matter Physics

Link to article, DOI:

10.1103/PhysRevE.69.031203

Publication date:

2004

Document Version

Publisher's PDF, also known as Version of record

Link back to DTU Orbit

Citation (APA):

Boned, C., Allal, A., Baylaucq, A., Zéberg-Mikkelsen, C., Bessieres, D., \& Cisneros, S. (2004). Simultaneous free-volume modeling of the self-diffusion coefficient and dynamic viscosity at high pressure. Physical Review $E$. Statistical, Nonlinear, and Soft Matter Physics, 69(3), 031203. https://doi.org/10.1103/PhysRevE.69.031203

\section{General rights}

Copyright and moral rights for the publications made accessible in the public portal are retained by the authors and/or other copyright owners and it is a condition of accessing publications that users recognise and abide by the legal requirements associated with these rights.

- Users may download and print one copy of any publication from the public portal for the purpose of private study or research.

- You may not further distribute the material or use it for any profit-making activity or commercial gain

- You may freely distribute the URL identifying the publication in the public portal 


\title{
Simultaneous free-volume modeling of the self-diffusion coefficient and dynamic viscosity at high pressure
}

\author{
C. Boned, ${ }^{1, *}$ A. Allal, ${ }^{2}$ A. Baylaucq, ${ }^{1}$ C. K. Zéberg-Mikkelsen, ${ }^{1}$ D. Bessieres, ${ }^{1}$ and S. E. Quiñones-Cisneros ${ }^{3}$ \\ ${ }^{1}$ Laboratoire des Fluides Complexes, CNRS UMR No. 5150, Faculté des Sciences et Techniques, Université de Pau, \\ Avenue de l'Université, Boîte Postale 1155, 64013 Pau Cedex, France \\ ${ }^{2}$ Laboratoire de Physico-Chimie des Polymères, UMR CNRS 5067, Faculté des Sciences et Techniques, \\ Université de Pau, Avenue de l'Université, Boite Postale 1155, 64013 Pau Cedex, France \\ ${ }^{3}$ Center for Phase Equilibria and Separation Processes (IVCSEP), Department of Chemical Engineering, \\ Technical University of Denmark, Building 229, 2800 Kgs Lyngby, Denmark
}

(Received 16 October 2002; revised manuscript received 12 November 2003; published 25 March 2004)

In this work, a simultaneous modeling of the self-diffusion coefficient and the dynamic viscosity is presented. In the microstructural theory these two quantities are governed by the same friction coefficient related to the mobility of the molecule. A recent free-volume model, already successfully applied to dynamic viscosity, has been considered and generalized. In this generalized model the compound is characterized by only four parameters. But if the quadratic length is known, the number of adjustable parameters is three. The compounds considered in this work are benzene, carbon tetrachloride, chlorotrifluoromethane, cyclohexane, methylcyclohexane, and tetramethylsilane. For these pure compounds we have found in the literature several data for both the self-diffusion and the dynamic viscosity in large viscosity, diffusion, temperature, and pressure intervals (up to around $500 \mathrm{MPa}$ for methylcyclohexane and tetramethylsilane). The average absolute deviation obtained by the modeling is generally less than $3 \%$ for the viscosity and $5 \%$ for the self-diffusion.

DOI: 10.1103/PhysRevE.69.031203

PACS number(s): 66.20.+d, 66.10. $-\mathrm{x}, 62.40 .+\mathrm{i}$

\section{INTRODUCTION}

Very recently [1] in a work on molecular dynamic it has been stressed that the pressure $(P)$ dependence of transport properties (in particular the dynamic viscosity $\eta$ and the selfdiffusion coefficient $D$ ) has drawn much less attention compared to their temperature $(T)$ dependence. Many questions regarding pressure dependence are still either not known or poorly understood. In particular the authors [1] wondered what is the correlation between the pressure and temperature dependence of viscosity and diffusion and they said that they were not aware if these questions have already been satisfactorily answered. In their paper the authors carried out extensive molecular dynamic simulations with the Kob-Andersen model of binary mixtures emphasizing the role of the free volume. In the same opinion a connection between the generic van der Waals equation of state and the self-diffusion coefficient of liquids has recently been proposed [2] with the free volume computed from the cavity function obtained by means of a Monte Carlo cavitation method and some comparisons have been made on spherical molecules (argon and methane in approximation). The dynamic viscosity was not considered in this work. Nevertheless, Liu et al. [3] have proposed a generalized free-volume theory for transport properties and new trends about the relationship between the free volume and equations of state, considering both dynamic viscosity and self-diffusion coefficient.

In this work we intend to use the link that appears between dynamic viscosity and self-diffusion coefficient in microscopic theory. It has theoretically been demonstrated (see

\footnotetext{
*Author to whom correspondence should be addressed. Email address: christian.boned@univ-pau.fr
}

for instance Refs. [4,5]) that the viscosity in the dense state may be written as

$$
\Delta \eta=\frac{\rho N_{a} \zeta L^{2}}{M}
$$

where $N_{a}$ is Avogadro's number, $\zeta$ the friction coefficient of a molecule, $L$ the average characteristic molecular quadratic length, $\rho$ the density of the compound and $M$ the molecular weight. The friction coefficient $\zeta$ is related to the mobility of the molecule. The self-diffusion coefficient has often been theoretically developed (see, for instance, Refs. [6-9]) and particularly for small molecules by Doi and Edwards [6] in the case of the Rouse theory, obtaining the following expression:

$$
D=\frac{k T}{\zeta}
$$

The combination of Eqs. (1) and (2) leads to $D M \Delta \eta / \rho R T$ $=L^{2}$ (where $R=k N_{a}$ is the ideal gas constant). This equation is similar to $D M \Delta \eta / \rho R T=\delta^{2} / 2$ which corresponds to the so-called Dullien's invariant $[8,10]$ first derived by using Lamm's theory in order to evaluate a molar average friction coefficient. In this equation the parameter $\delta$ is the average momentum transfer distance. The Dullien's invariant is not based on any particular model of the liquid state and is expected to hold for Newtonian liquids. Dullien showed that his equation is consistent with elementary kinetic theory.

Equations (1) and (2) show that an important issue is the evaluation of the molecular friction coefficient $\zeta$. In the following we will present and use a possibility related to the expression of $\zeta$ proposed in a recent free-volume model for the dynamic viscosity $[5,11]$. This model has been introduced in order to model the viscosity of Newtonian fluids in 
TABLE I. Deviations obtained with the free-volume model, using four parameters.

\begin{tabular}{|c|c|c|c|c|c|c|c|c|}
\hline & $\mathrm{C}_{6} \mathrm{H}_{6}$ & $\mathrm{CClF}_{3}$ & $\mathrm{C}_{6} \mathrm{H}_{12}$ & $\mathrm{C}_{7} \mathrm{H}_{14}$ & $\begin{array}{c}\mathrm{C}_{7} \mathrm{H}_{14} \\
(P \leqslant 200 \mathrm{MPa})\end{array}$ & $\mathrm{CCl}_{4}$ & $\mathrm{C}_{4} \mathrm{H}_{12} \mathrm{Si}$ & $\begin{array}{c}\mathrm{C}_{4} \mathrm{H}_{12} \mathrm{Si} \\
(P \leqslant 210 \mathrm{MPa})\end{array}$ \\
\hline$L(\AA)$ & 2.177 & 1.76447 & 2.38095 & 2.66377 & 2.63858 & 2.082716 & 2.086599 & 2.1263 \\
\hline$b_{f}(\AA)$ & 8.43783 & 7.39201 & 8.45667 & 10.9092 & 10.04008 & 5.88255 & 6.665568 & 6.23138 \\
\hline $\begin{array}{l}\alpha \\
\left(\mathrm{J} \mathrm{m}^{3} / \mathrm{mol} / \mathrm{kg}\right)\end{array}$ & 73.9411 & 23.5357 & 75.2126 & 100.2599 & 90.59632 & 38.10547 & 92.78703 & 81.1812 \\
\hline$B$ & 0.011458 & 0.015659 & 0.017541 & 0.009414 & 0.010825 & 0.012222 & 0.007363 & 0.008731 \\
\hline $\mathcal{D}_{\mathrm{av}, D}(\%)$ & 2.14 & 3.09 & 1.56 & 8.50 & 5.06 & 3.08 & 5.85 & 4.05 \\
\hline $\mathcal{D}_{\max , D}(\%)$ & 8.68 & 11.31 & 5.75 & 27.34 & 14.69 & 8.2 & 17.88 & 10.88 \\
\hline $\mathcal{B}_{D}(\%)$ & 0.17 & -0.37 & -0.025 & 2.29 & -0.52 & 0.68 & 2.46 & 1.91 \\
\hline $\mathcal{D}_{\mathrm{av}, \eta}(\%)$ & 0.84 & 3.85 & 1.74 & 6.35 & 2.23 & 1.084 & 2.33 & 2.64 \\
\hline $\mathcal{D}_{\max , \eta}(\%)$ & 7.97 & 8.29 & 5.95 & 22.76 & 6.69 & 4.50 & 8.58 & 11.36 \\
\hline $\mathcal{B}_{\eta}(\%)$ & -0.18 & 0.097 & -0.30 & -1.82 & -0.26 & -0.15 & -0.83 & 1.21 \\
\hline
\end{tabular}

both gaseous and dense states. It has been successfully applied to various hydrocarbons [5] over wide ranges of temperature and pressure. For instance this model can represent the data of methane (database of 885 points) from $0.01 \mathrm{MPa}$ to $200 \mathrm{MPa}$ and from $90.7 \mathrm{~K}$ to $600 \mathrm{~K}$ (i.e., from dilute gas to dense state) with an average absolute deviation of $2.59 \%$ and a maximum deviation of $14.8 \%$ at $P=200 \mathrm{MPa}$. The model has also been applied at high pressure, i.e., above 250 $\mathrm{MPa}$ and sometimes up to $500 \mathrm{MPa}$, to benzene $(0.72 \%$ and $6.56 \%)$, trans-decalin $(2.03 \%$ and $8.34 \%), n$-hexane $(1.09 \%$ and $6.50 \%), n$-dodecane $(3.51 \%$ and $18.5 \%)$ and $n$-octane $(2.51 \%$ and $19.6 \%)$ data. The pressure, temperature and viscosity intervals are sufficiently large to verify that the viscosity free-volume model is not a local fit of the data.

\section{PRESENTATION OF THE MODEL}

In the free-volume approach used in this work, the total dynamic viscosity is given by $\eta=\eta_{0}+\Delta \eta$. The first term is a dilute gas contribution and the second one $\Delta \eta$ is the dense state contribution. The dilute gas viscosity $\eta_{0}$ is defined as the viscosity at the dilute gas limit and, for several fluids can be accurately represented by the Chung et al. model [12]. The applied approach connects the term $\Delta \eta$ to molecular structure via a representation of the free volume fraction. The viscosity, in this theory, appears as being the product of the fluid modulus $\rho R T / M$ by the mean relaxation time of the molecule defined by $L^{2} \zeta /(k T)$. The friction coefficient $\zeta$ is related to the mobility of the molecule and to the diffusion process Eq. (2). Notice here that in the case of the theoretical explanation of the movement of a colloidal particle at infinite dilution Eq. (2) is the Einstein equation. The use of the expression of the friction coefficient for a macroscopic sphere gives the Stokes-Einstein relation. But here, the friction coefficient has to be the one associated with a molecule and we use a free volume framework as developed in Ref. [5]. As Doolittle [13] has shown, this coefficient is governed by the free volume fraction $f_{v}=v_{f} / v$ where $v$ is the specific molecular volume; $v_{0}$ the molecular volume of reference or hard-core volume, and $v_{f}=\left(v-v_{0}\right)$. At temperature $T$ it has been shown [5] that $f_{v}=(R T / E)^{3 / 2}$. To establish this relation it is assumed that the molecule moves in a potential field controlled by the intermolecular energy $E$ due to the neighboring molecules. This intermolecular energy can be approximated [5] by $E=\alpha \rho+P M / \rho$ where the term $P M / \rho$ $=P V$ is connected to the energy necessary to form the vacant vacuums available for the diffusion of the molecules. $E_{0}=\alpha \rho$ is connected to the energy barrier that the molecule has to exceed in order to diffuse. With these hypotheses and using the Doolittle result [13], which has later been theoretically justified by Cohen and Turnbull [14], Allal et al. [5] have shown that the viscosity of the dense state is given by

$$
\Delta \eta=\frac{\rho N_{a} L^{2} \zeta_{0} \exp \left(B / f_{v}\right)}{M},
$$

where $B$ characterizes the free volume overlap, and

$$
\zeta_{0}=\frac{E}{N_{a} b_{f}} \sqrt{\frac{M}{3 R T}},
$$

where $b_{f}$ is the dissipation length of the energy $E$. Finally,

$$
\eta=\eta_{0}+\frac{\rho L^{2}\left(\alpha \rho+\frac{P M}{\rho}\right)}{b_{f} \sqrt{3 R T M}} \exp \left(B\left(\frac{\alpha \rho+\frac{P M}{\rho}}{R T}\right)^{3 / 2}\right) .
$$

This equation involves four physical parameters characterizing the molecule: $L, b_{f}, \alpha$, and $B$. However, as it is shown below, $L$ can be evaluated independently and the number of parameters reduces to three. Combining Eqs. (1) to (3) it follows for the self-diffusion coefficient:

$$
D=\frac{R T b_{f}}{\alpha \rho+\frac{P M}{\rho}} \sqrt{\frac{3 R T}{M}} \exp \left(-B\left(\frac{\alpha \rho+\frac{P M}{\rho}}{R T}\right)^{3 / 2}\right),
$$

which involves the same parameters as for the dynamic viscosity: $b_{f}, \alpha$ and $B$. In the following section, Eqs. (3) and (4) are regressed to experimental $D$ and $\eta$ data for several compounds over wide temperature and pressure intervals, corre- 


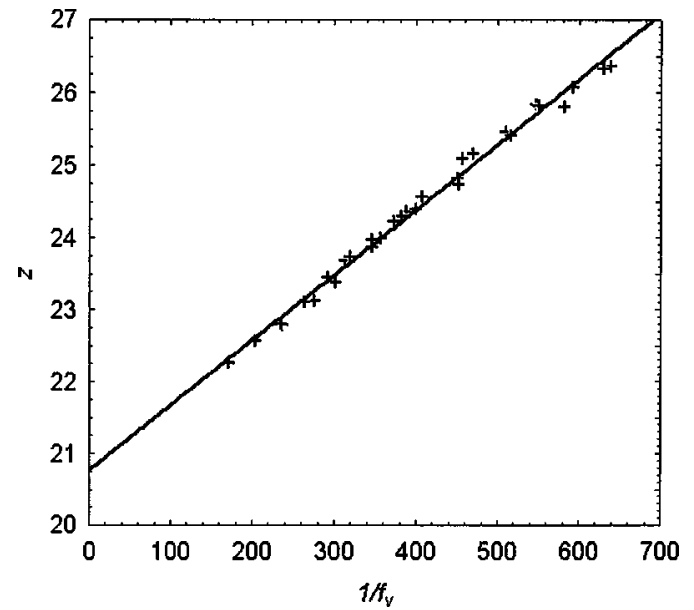

FIG. 1. Variations of $z$ versus $1 / f_{v}$ in the case of methylcyclo-

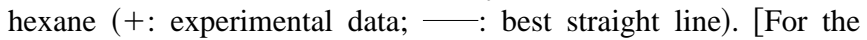
calculation of $z$ all the units are in SI and the value for $1 / f_{v}=0$ allows us to evaluate $\ln \left(b_{f}\right)$ with $b_{f}$ expressed in meters.]

sponding to large viscosity and self-diffusion intervals, in order to show the coherence of this description.

\section{DATABASE AND CHARACTERIZATION OF THE RESULTS}

The main purpose of this paper is to show that the highpressure dynamic viscosity and self-diffusion coefficient behavior can be modeled using strictly the same molecular parameters. Additionally, the average characteristic molecular quadratic length $L$ values evaluated from those models are compared with the values obtained with an independent method.

The following substances have been considered in this work.

Benzene [15,16]: $\mathrm{C}_{6} \mathrm{H}_{6}, \quad M=78.113 \mathrm{~g} / \mathrm{mol}, 39$ values for $\eta$ (estimated $2 \%$ uncertainty) and 39 values for $D$ ( $2 \%$ up to $4 \%$ uncertainty), between $288.2 \mathrm{~K} \leqslant T \leqslant 333.2 \mathrm{~K}$ and $0.101 \mathrm{MPa} \leqslant P \leqslant 154.4 \mathrm{MPa}$. Viscosity range 0.390 $<\eta<1.157 \mathrm{mPa}$. Self-diffusion range $1.36<D$ $<3.69910^{-9} \mathrm{~m}^{2} \mathrm{~s}^{-1}$.

Chlorotrifluoromethane [17]: $\mathrm{CClF}_{3}, M=104.459 \mathrm{~g} / \mathrm{mol}$, 26 values for $\eta$ (uncertainty not indicated) between $303.15 \mathrm{~K} \leqslant T \leqslant 348.15 \mathrm{~K}$ and $5 \mathrm{MPa} \leqslant P \leqslant 60 \mathrm{MPa}$ and 67 values for $D(2 \%$ uncertainty), between $303.15 \mathrm{~K} \leqslant T$ $\leqslant 348.15 \mathrm{~K}$ and $3.68 \mathrm{MPa} \leqslant P \leqslant 188.38 \mathrm{MPa}$. However the curve $\eta(P)$ at $303.15 \mathrm{~K}$ seems to show that the viscosity value at $5 \mathrm{MPa}$ is not correct (perhaps a typographical mistake). So this point has not been included in the calculation. Viscosity range $0.019<\eta<0.189 \mathrm{mPa}$. Self-diffusion range $3.20<D<60.210^{-9} \mathrm{~m}^{2} \mathrm{~s}^{-1}$.

Cyclohexane [18]: $\quad \mathrm{C}_{6} \mathrm{H}_{12}, \quad M=84.161 \mathrm{~g} / \mathrm{mol}, \quad 25$ values for $\eta$ (uncertainty not indicated) between $313 \mathrm{~K}$ $\leqslant T \leqslant 383 \mathrm{~K}$ and $0.1 \mathrm{MPa} \leqslant P \leqslant 210 \mathrm{MPa}$ and 39 values for $D$ (uncertainty not indicated), between $313 \mathrm{~K} \leqslant T$ $\leqslant 383 \mathrm{~K}$ and $0.1 \mathrm{MPa} \leqslant P \leqslant 214 \mathrm{MPa}$. Viscosity range $0.319<\eta<1.72 \mathrm{mPas}$. Self-diffusion range $1.03<D$ $<5.23710^{-9} \mathrm{~m}^{2} \mathrm{~s}^{-1}$.
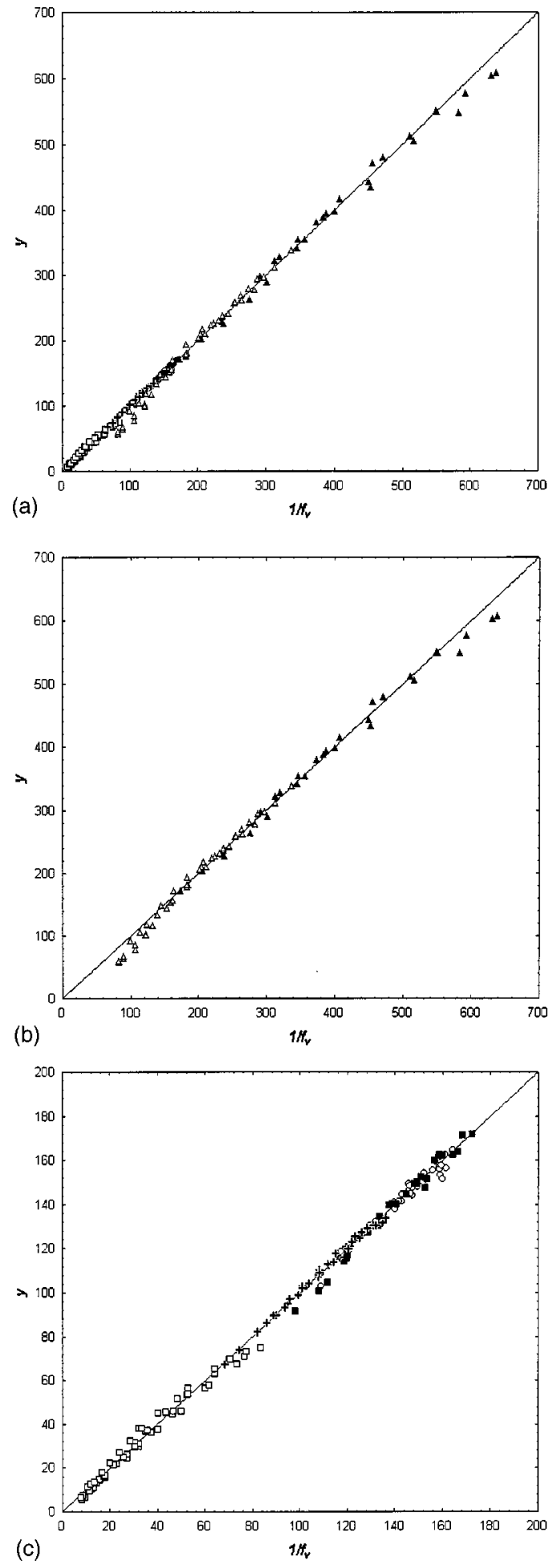

FIG. 2. Master curve $y$ versus $1 / f_{v}$. (a) All the data. $\bigcirc$ : benzene; $\mathbf{\square}: \mathrm{CCl}_{4} ; \square$ : chlorotrifluoromethane; + : cyclohexane; $\mathbf{\Delta}$ : methylcyclohexane; $\triangle$ : tetramethylsilane; — : first bisectrix. (b) $\boldsymbol{\Delta}$ : methylcyclohexane; $\triangle$ : tetramethylsilane; — : first bisectrix. (c) $\bigcirc$ : benzene; $\mathbf{\square}: \mathrm{CCl}_{4}$; $\square$ : chlorotrifluoromethane; + : cyclohexane; - : first bisectrix.

Methylcyclohexane [19]: $\mathrm{C}_{7} \mathrm{H}_{14}, M=98.188 \mathrm{~g} / \mathrm{mol}, 22$ values for $\eta$ (uncertainty not indicated) between $223 \mathrm{~K} \leqslant T$ $\leqslant 298 \mathrm{~K}$ and $0.1 \mathrm{MPa} \leqslant P \leqslant 500 \mathrm{MPa}$ and 30 values for $D$ ( $5 \%$ uncertainty up to $15 \%$ at higher pressures), between 
TABLE II. Comparison between the $L$ values (in $\AA$ ) obtained in this work and calculated with a group contribution method [28].

\begin{tabular}{lllllllll}
\hline \hline & & & & & $\mathrm{C}_{7} \mathrm{H}_{14}$ & & & \\
& $\mathrm{C}_{6} \mathrm{H}_{6}$ & $\mathrm{CClF}_{3}$ & $\mathrm{C}_{6} \mathrm{H}_{12}$ & $\mathrm{C}_{7} \mathrm{H}_{14}$ & $(P \leqslant 200 \mathrm{MPa})$ & $\mathrm{CCl}_{4}$ & $\mathrm{C}_{4} \mathrm{H}_{12} \mathrm{Si}$ & $(P \leqslant 210 \mathrm{MPa})$ \\
\hline$L$ (free volume) & 2.177 & 1.76447 & 2.38095 & 2.66377 & 2.63858 & 2.082716 & 2.086599 & 2.1263 \\
$L$ (calculated) & 2.1069 & 1.8349 & 2.2306 & 2.3629 & 2.3629 & 2.1257 & 2.3316 & 2.3316 \\
\hline \hline
\end{tabular}

$203 \mathrm{~K} \leqslant T \leqslant 298 \mathrm{~K}$ and $0.1 \mathrm{MPa} \leqslant P \leqslant 500 \mathrm{MPa}$. The data point $P=150 \mathrm{MPa}$ and $T=203 \mathrm{~K}$ is obviously erroneous and has not been considered. Viscosity range $0.683<\eta$ $<71.38 \mathrm{mPas}$. Self-diffusion range $0.012<D$ $<1.91510^{-9} \mathrm{~m}^{2} \mathrm{~s}^{-1}$.

Tetrachloride carbon [20]: $\mathrm{CCl}_{4}, M=153.823 \mathrm{~g} / \mathrm{mol}, 27$ values for $\eta$ (estimated $2 \%$ uncertainty) and 27 values for $D$ ( $2 \%$ up to $4 \%$ uncertainty), between $283.2 \mathrm{~K} \leqslant T$ $\leqslant 328.2 \mathrm{~K}$ and $0.101 \mathrm{MPa} \leqslant P \leqslant 147.5 \mathrm{MPa}$. Viscosity range $0.62<\eta<2.28 \mathrm{mPa}$. Self-diffusion range $0.51<D$ $<2.0810^{-9} \mathrm{~m}^{2} \mathrm{~s}^{-1}$.

Tetramethylsilane [21,22]: $\quad \mathrm{C}_{4} \mathrm{H}_{12} \mathrm{Si}, \quad M=88.22 \mathrm{~g} / \mathrm{mol}$, 45 values for $\eta$ (uncertainty not indicated) between $298 \mathrm{~K}$ $\leqslant T \leqslant 373 \mathrm{~K}$ and $4.6 \mathrm{MPa} \leqslant P \leqslant 450 \mathrm{MPa}$ and 42 values for $D$ (uncertainty not indicated), between $298 \mathrm{~K} \leqslant T$ $\leqslant 373 \mathrm{~K}$ and $4.5 \mathrm{MPa} \leqslant P \leqslant 450 \mathrm{MPa}$. Viscosity range $0.173<\eta<3.805 \mathrm{mPa}$. Self-diffusion range $0.329<D$ $<7.46610^{-9} \mathrm{~m}^{2} \mathrm{~s}^{-1}$.

These substances are in the dense state, and the pressures up to 500 and $450 \mathrm{MPa}$ for methylcyclohexane and tetramethylsilane respectively, allowing to verify the performance of the model up to high pressure. In fact not only the pressure interval but also the temperature, viscosity and selfdiffusion intervals are sufficiently large to check that the presented expressions are not a local fit of the data. For these six compounds the total number of data is 185 for the dynamic viscosity and 245 for the self-diffusion coefficient. All of the scaling parameters required in the Chung et al. dilute gas viscosity model [12] have been taken from Reid et al. [23]. However, in the case of tetramethylsilane, the critical constants were taken from the compendium by Simmrock et al. [24], and the acentric factor was estimated after an optimization of the normal boiling temperature with the PengRobinson equation of state [25]. We estimated for this compound: $T_{c}=448.6 \mathrm{~K}, P_{c}=2.82 \mathrm{MPa}, V_{c}=361 \mathrm{~cm}^{3} / \mathrm{mol}$ and $\omega=0.2426$. Concerning the evaluation of $\eta_{0}$ it is important to stress that in the dense state the dilute gas viscosity is negligible in comparison to the total viscosity.

In order to validate and compare the performance of the considered models it is necessary to introduce characteristic quantities of the results obtained. For instance, for dynamic viscosity, the following quantities are defined:

$$
\begin{gathered}
d_{i, \eta}=\left(1-\eta_{\mathrm{calc}, i} / \eta_{\mathrm{expt}, i}\right) 100 \%, \\
\mathcal{D}_{\mathrm{av}, \eta}=\frac{1}{N_{b}} \sum_{i=1}^{N_{b}}\left|d_{i, \eta}\right|,
\end{gathered}
$$

$$
\begin{gathered}
\mathcal{B}_{\eta}=\frac{1}{N_{b}} \sum_{i=1}^{N_{b}} d_{i, \eta}, \\
\mathcal{D}_{\max , \eta}=\max \left|d_{i, \eta}\right|,
\end{gathered}
$$

in which $N_{b}$ is the number of experimental points, $\eta_{\text {expt }}$ the measured viscosity and $\eta_{\text {calc }}$ the calculated value. The equivalent quantities are defined for self-diffusion coefficient substituting " $D$ " in place of " $\eta$." The quantity $\mathcal{D}_{\text {av }}$ (average absolute deviation) indicates how close the calculated values are to the experimental values and the quantity $\mathcal{B}$ indicates how well the experimental points are distributed around the calculated curves. If $\mathcal{B}=\mathcal{D}_{\text {av }}$ then all of the experimental points are above the calculated curves. Finally, $\mathcal{D}_{\max }$ characterizes the maximum absolute deviation that is obtained using a given representation.

\section{RESULTS OF THE NUMERICAL ANALYSIS}

Table I displays the results obtained with this model, fitting simultaneously the four parameters $L, b_{f}, \alpha$ and $B$. In the case of methylcyclohexane and tetramethylsilane the results have been obtained first considering only data up to around $200 \mathrm{MPa}$ and then all the data up to around $500 \mathrm{MPa}$. Clearly, when the pressure is limited to $P \leqslant 200 \mathrm{MPa}$ an important improvement is appreciated: $\mathcal{D}_{\max , D}$ falls from $27.3 \%$ to $14.7 \%$ and $\mathcal{D}_{\max , \eta}$ from $22.8 \%$ to $6.7 \%$. This may in part be due to the larger uncertainty for the high pressure measurements and we could consider that a good agreement between experimental and calculated values for viscosity and diffusion coefficient as shown in Table I, even at pressure up to $500 \mathrm{MPa}$. Not only the pressure interval $(0.1<P$ $<500 \mathrm{MPa})$, but also the temperature $(203<T<373 \mathrm{~K})$, viscosity $(0.019<\eta<71.38 \mathrm{mPa} \mathrm{s})$ and self-diffusion coefficient $\left(0.012<D<60.210^{-9} \mathrm{~m}^{2} \mathrm{~s}^{-1}\right)$ intervals are sufficiently large to conclude that the presented expressions are not a local fit of the data.

Using the experimental values $D_{\text {expt }}$ of the diffusion coefficient the quantity $z=-\ln \left(D_{\text {expt }} E / R T \sqrt{M / 3 R T}\right)$ is calculated. In order to evaluate $E$ the estimated value of $\alpha$ given in Table I is used, as $E=\alpha \rho+P M / \rho$. Following Eq. (4) one has $z=-\ln \left(b_{f}\right)+B(E / R T)^{3 / 2}$ and the curve $z$ versus $(E / R T)^{3 / 2}=1 / f_{v}$ should be a straight line. The slope allows to evaluate $B$ and the value for $1 / f_{v}=0$ allows to evaluate $\ln \left(b_{f}\right)$, i.e., $b_{f}$. Figure 1 corresponds to the worst case of Table I, i.e., for methylcyclohexane up to $500 \mathrm{MPa}$. (For this figure $b_{f}$ is expressed in meters because for the calculation of $z$ all the units are in SI.) The numerical analysis of the straight line gives $B=0.00903\left(0.009414\right.$ in Table I) and $b_{f}$ 
TABLE III. Deviations obtained with the free-volume model, using three parameters and the $L$ values calculated with a group contribution method [28].

\begin{tabular}{|c|c|c|c|c|c|c|c|c|}
\hline & $\mathrm{C}_{6} \mathrm{H}_{6}$ & $\mathrm{CClF}_{3}$ & $\mathrm{C}_{6} \mathrm{H}_{12}$ & $\mathrm{C}_{7} \mathrm{H}_{14}$ & $\begin{array}{c}\mathrm{C}_{7} \mathrm{H}_{14} \\
(P \leqslant 200 \mathrm{MPa})\end{array}$ & $\mathrm{CCl}_{4}$ & $\mathrm{C}_{4} \mathrm{H}_{12} \mathrm{Si}$ & $\begin{array}{c}\mathrm{C}_{4} \mathrm{H}_{12} \mathrm{Si} \\
(P \leqslant 210 \mathrm{MPa})\end{array}$ \\
\hline$b_{f}(\AA)$ & 9.97741 & 7.35437 & 8.4543 & 8.752098 & 7.732193 & 6.24395 & 6.298183 & 6.110199 \\
\hline $\begin{array}{l}\alpha \\
\left(\mathrm{J} \mathrm{m} \mathrm{m}^{3} / \mathrm{mol} / \mathrm{kg}\right)\end{array}$ & 75.68944 & 23.6037 & 75.8980 & 100.1666 & 92.95238 & 37.8817 & 79.6128 & 74.99682 \\
\hline$B$ & 0.01234 & 0.015080 & 0.017587 & 0.009038 & 0.009878 & 0.01256 & 0.008000 & 0.009120 \\
\hline $\mathcal{D}_{\mathrm{av}, D}(\%)$ & 4.1 & 3.28 & 3.63 & 9.96 & 11 & 3.68 & 16.28 & 8.91 \\
\hline $\mathcal{D}_{\max , D}(\%)$ & 13.4 & 12.3 & 9.39 & 27.03 & 21.6 & 8.58 & 30.55 & 20.08 \\
\hline $\mathcal{B}_{D}(\%)$ & 4.04 & -1.26 & 3.58 & 8.52 & 9.52 & -2.48 & -16.2 & -8.78 \\
\hline $\mathcal{D}_{\mathrm{av}, \eta}(\%)$ & 2.42 & 5.75 & 8.58 & 13.05 & 8.74 & 1.66 & 5.78 & 7.18 \\
\hline $\mathcal{D}_{\max , \eta}(\%)$ & 6.35 & 14.09 & 14.78 & 23.5 & 18.67 & 6.42 & 16.67 & 14.11 \\
\hline $\mathcal{B}_{\eta}(\%)$ & 2.36 & -5.30 & 8.58 & 13.05 & 8.74 & -1.1 & -5.61 & -6.87 \\
\hline
\end{tabular}

$=9.6226 \AA$ (10.9092 $\AA$ in Table I), but in that case the evaluations of $B$ and $b_{f}$ are independent of the viscosity, contrary to the values indicated in Table I, which take into account the viscosity behavior. In order to build a master curve, we have considered the dimensionless quantity $y=$ $-(1 / B) \ln \left(D_{\text {expt }} E / R T b_{f} \sqrt{M / 3 R T}\right)$ which, according to Eq. (4), is equal to $(E / R T)^{3 / 2}=1 / f_{v}$, and the curve $y$ versus $1 / f_{v}$ should be the first bisectrix. We used the $\alpha, B$ and $b_{f}$ values given in Table I, because they also take into account the viscosity behavior of the compounds. All the 245 diffusion coefficient data points are plotted on Fig. 2(a). The agreement is very good (the best line corresponds to $y=-0.318$ $\left.+0.9935 / f_{v}\right)$. This validates in some sense the $3 / 2$ power in the expression of $f_{v}$ versus $E / R T$. Concerning the $3 / 2$ power, the interested reader will find other theoretical considerations for free volume in Refs. [26], [27]. In order to clarify the figure, we plotted on Fig. 2(b) only tetramethylsilane and methylcyclohexane (up to $500 \mathrm{MPa}$ ) and on Fig. 2(c) we plotted benzene, chlorotrifluoromethane, cyclohexane, and tetrachloride carbon.

Another interesting point is that it is possible to evaluate the average characteristic molecular quadratic length $L^{2}$ by an independent method [28]. Assuming that the molecules are quasispherical (which is a reasonable hypothesis for the considered molecules), $L^{2}=3 / 5 r^{2}$ where $r$ is the molecular radius and $L$, the square root of the average characteristic molecular quadratic length, is the gyration radius. The molecular radius $r$ is estimated from the Van der Waals volume $\left(V_{W}\right)$ of the molecule calculated using a group contribution method [28] and $V_{W}=4 / 3 \pi r^{3}$. Table II shows a good agreement with both methods in the estimation of $L$. The worse case corresponds to tetramethylsilane and methylcyclohexane for which the spherical molecule hypothesis is not accurate enough resulting in a departure of about $10 \%$. The good agreement between the molecular size $L$ calculated in this work and the values evaluated by an independent method is an important point showing the pertinence of the used equations and their validity over wide viscosity and diffusion intervals. Finally Table III presents the results obtained using the calculated values of $L$ and fitting the remaining 3 parameters. This reduction of the number of adjustable parameters leads to slightly higher deviations but the results remain very good.

\section{CONCLUSIONS}

The objective of this work was to simultaneously model and predict the temperature-pressure variations of the dynamic viscosity and the self-diffusion coefficient of small molecules from the knowledge of the molecular dimensions and the energy of interaction, using the free-volume concept. To our knowledge no such simultaneous modeling, with numerical checking in such large pressure, temperature, viscosity and self-diffusion intervals, exists in the literature.

The results of this work show three key points.

(1) The satisfying agreement between our model and the experimental results is due to the good modeling of the molecular friction coefficient $\zeta$. The correct definition of this last property is made possible by the use of the well-known microscopic theory relation between dynamic viscosity and self-diffusion coefficient.

(2) The relationship between the viscosity and the selfdiffusion coefficient involves the molecular dimension $L$. The results of this paper show a good agreement between the fitted molecular size parameter and the actual dimension of the studied molecules. This dimension can be calculated using an independent molecular mechanical approach.

(3) The last key point concerns the energy of interaction $E$. The relationship between the energy and the density is an interesting ersatz but in reality we have to determine it from the electronic structure of the molecules and their spatial conformations: molecular dynamic could be a good way to do it.

Finally, this model emphasizes the relation between microstructure, free volume, and different complex thermophysical properties such as dynamic viscosity and selfdiffusion coefficient. Thus, this approach may also lead to a better understanding of the relationship between a larger set of properties. In a future work the relationship between free volume, dynamic viscosity, self-diffusion coefficient and other properties will be considered. 
[1] A. Mukherjee, S. Bhattacharyya, and B. Bagchi, J. Chem. Phys. 116, 4577 (2002).

[2] K. Rah and B. C. Eu, J. Chem. Phys. 115, 2634 (2001).

[3] H. Liu, C. M. Silva, and E. A. Macedo, Fluid Phase Equilib. 202, 89 (2002).

[4] F. Bueche, J. Chem. Phys. 20, 1259 (1952).

[5] A. Allal, C. Boned, and A. Baylaucq, Phys. Rev. E 64, 011203/1 (2001).

[6] (a) M. Doi and S. F. Edwards, J. Chem. Soc., Faraday Trans. 2 74, 1789 (1978); (b) M. Doi and S. F. Edwards, The Theory of Polymer Dynamics (Oxford University Press, New York, 1986), p. 95.

[7] P. E. Rouse, Jr., J. Chem. Phys. 21, 1272 (1953).

[8] F. A. L. Dullien, Trans. Faraday Soc. 59, 856 (1963).

[9] J. H. Kim and S. H. Lee, Bull. Korean Chem. Soc. 23, 447 (2002).

[10] F. A. L. Dullien, AIChE J. 18, 62 (1972).

[11] A. Allal, M. Moha-Ouchane, and C. Boned, Phys. Chem. Liq. 39, 1 (2001).

[12] T. H. Chung, M. Ajlan, L. L. Lee, and K. E. Starling, Ind. Eng. Chem. Res. 27, 671 (1988).

[13] A. K. Doolittle, J. Appl. Phys. 22, 1471 (1951).

[14] M. H. Cohen and D. Turnbull, J. Chem. Phys. 31, 1164 (1959).

[15] M. A. McCool, A. F. Collings, and L. A. Woolf, J. Chem. Soc., Faraday Trans. 1 68, 1489 (1972).
[16] A. F. Collings and L. A. Woolf, J. Chem. Soc., Faraday Trans. 1 71, 2296 (1975).

[17] K. R. Harris, Physica A 93, 593 (1978).

[18] J. Jonas, D. Hasha, and S. G. Huang, J. Phys. Chem. 84, 109 (1980).

[19] J. Jonas, D. Hasha, and S. G. Huang, J. Phys. Chem. 71, 3996 (1979).

[20] M. A. McCool and L. A. Woolf, J. Chem. Soc., Faraday Trans. 168,1971 (1972).

[21] H. J. Parkhurst, Jr. and J. Jonas, J. Chem. Phys. 63, 2698 (1975).

[22] H. J. Parkhurst, Jr. and J. Jonas, J. Chem. Phys. 63, 2705 (1975).

[23] R. C. Reid, J. M. Prausnitz, and B. E. Poling, in The Properties of Gases and Liquids, 4th ed. (MacGraw-Hill, New York, 1987).

[24] K. H. Simmrock, R. Janowsky, and A. Ohnsorge, in Critical Data of Pure Substances. 1: Ag- $\mathrm{C}_{7}$ DECHEMA Chemistry Data Series, Vol. II, Part 1, edited by D.Behrens and R. Eckermann (DECHEMA, Frankfurt/Main, 1986).

[25] D. Y. Peng and D. B. Robinson, Ind. Eng. Chem. Fundam. 15, 59 (1976).

[26] F. Bueche, Physical Properties of Polymers (Interscience, New York, 1962).

[27] M. H. Litt, Trans. Soc. Rheol. 20, 47 (1976).

[28] D. W. Van Krevelen, Properties of Polymers (Elsevier, Amsterdam, 1976). 